\title{
EDITORIAL
}

\section{LIFESTYLE AND AGING}

\author{
P. de Souto Barreto ${ }^{1,2}$ \\ Editor in Chief \\ The Journal of Aging and Lifestyle
}

In 2012, under the auspices of the International Association of Gerontology \& Geriatrics and the International Academy of Nutrition \& Aging, the Journal of Aging Research and Clinical Practice was launched to stimulate academic geriatric medicine worldwide, in particular in developing countries which experience high rates of growth in the older adult population. In its first number, the Journal published articles on the topics of exercise (1), nutrition (2), biological aspects of aging (3), smoking and alcohol consumption (4). Throughout its seven years of life, the Journal has published several papers on lifestyle and related topics. Recognizing the crucial role played by behaviors on the health of individuals and populations during the aging process, the Journal is now evolving its scope to focus on lifestylerelated research. On the sake of consistency, the title of the Journal is also changing, becoming from 2020 onwards the Journal of Aging Research \& Lifestyle JARLife.

Indeed, lifestyle behaviors are major determinants of how we age. The term "lifestyle" is a relatively recent concept in the scientific medical literature. Since its scientific birth in the early 70 s, lifestyle research has been linked to the field of gerontology and geriatrics, with the first original report using the term lifestyle in its title being performed in older adults (5). One of the first articles relating the term lifestyle to behaviors that have an impact on health during aging was published by Roy J. Shephard, in 1974 (6); in that paper, the author listed diet, physical activity, and smoking as important determinants of ischemic heart disease. Since this publication, the field of (un)healthy lifestyles and aging has enormously progressed: today, the scientific community consensually recognizes the importance not only of physical activity and exercise (7-9), nutrition-related aspects $(8,10)$, and

1. Gerontopole of Toulouse, Institute of Ageing, Toulouse University Hospital (CHU Toulouse), Toulouse, France; 2. UPS/Inserm UMR1027, University of Toulouse III, Toulouse, France

Corresponding Author: Professor Philipe de Souto Barreto, Gérontopôle de Toulouse, Institut du Vieillissement, 37 Allées Jules Guesde, F-31000 Toulouse, France, Phone: (+33) 561145 636, Fax: (+33) 561145 640, e-mail: philipebarreto81@yahoo.com.br

Received December 26, 2019

Accepted for publication December 27, 2019 smoking $(8,11)$, but also cognitive-stimulating activities (12), alcohol consumption (13), sedentary time (7) (which should not be understood as a synonym of low physical activity) and other lifestyle behaviors as major determinants of individual's as well as population's trajectories of health during the aging process.

According to the Global Burden of Diseases, Injuries, and Risk Factors Study (GBD) (8), worldwide data from 2017 showed that smoking, alcohol consumption, low consumption of whole grains and fruits and high consumption of sodium, and low physical activity levels were amongst the most deleterious unhealthy behaviors in the globe, being responsible for millions of deaths and tens of millions of disability-adjusted life years (DALY). What is less often said, but equally true, is that healthy lifestyle behaviors not only decrease early mortality and the onset and severity of numerous agerelated chronic diseases, but also improve functional ability (14) and functional capacities $(9,15,16)$ during aging, such as, mobility, cognitive and psychological capacities. Moreover, lifestyles, which are modifiable behaviors, interact with non-modifiable factors (eg, genetics) to determine individuals' health (17). They may work synergistically in order to determine the quality of individuals' aging, with the addition of healthy behaviors increasing the chances of experiencing a healthy aging (18).

The absence of a scientific Journal specifically dedicated to the essential topic of lifestyle during aging is no longer a gap for the field of gerontology and geriatrics. The Journal of Aging Research \& Lifestyle is committed in publishing high-quality research on all areas related to lifestyle and aging. The Journal has five initial sections that aims to cover the broad spectrum of lifestyle research during aging: 1 . Physical activity, exercise and aging; 2 . Nutrition and aging; 3 . Cognitive stimulation and aging; 4 . Geroscience and lifestyle; 5. Digital aspects, lifestyle and aging. Research on other lifestyle topics not covered into the above mentioned sections are also welcome. Original investigations using all types of study designs, from 
observational investigations to interventions, but also qualitative studies, are accepted, as well as other types of articles, such as Reviews, Meta-Analyses, Comments / Perspectives, Letters-to-the-Editor, Methodological papers and Research Protocols. High priority will be given to studies investigating the interactions of multiple health behaviors during aging, in particular, clinical trials of multidomain lifestyle interventions (when two or more lifestyle interventions are combined $(19,20))$ as well as observational longitudinal studies that have assessed several lifestyle behaviors over time. Reports using a lifecourse perspective are also welcome. Although our main focus regards research in humans, cutting-edge animal studies may be considered.

As an exercise scientist and Editor-in-Chief of the Journal of Aging Research and Lifestyle, I am honored and pleased to have the possibility to provide, on one hand, a broader space to the scientific community to publish high-quality articles on lifestyle-related topics and, on the other hand, an outstanding tool for researchers and health professionals working in a daily basis to promote healthy behaviors durably during aging. With its international Editorial Board, composed of a mix of senior renowned experts and outstanding young researchers from different backgrounds, the Journal recognizes the importance of cultural aspects on lifestyle behaviors and takes into account the multiplicity of lifestyle-related fields, including (but not limited to): nutrition, exercise, cognitive stimulation, gerosciences and basic sciences, geriatrics, epidemiology, and eHealth. We deliberately opted to have a small, but very motivated and competent Editorial Board, composed of high-level researchers committed in building a successful and scientifically rigorous Journal.

By publishing articles with the highest standards of both scientific quality and clarity in the report, I am convinced the Journal of Aging Research and Lifestyle will foster advances in the field of gerontology and geriatrics, and will facilitate the translation of research findings into clinical practice, with the ultimate aim of contributing to promote a healthy aging all around the world.

\section{References}

1. Meneses $\mathrm{Y}$, Vale $\mathrm{R}$, Andrade A. Carotid resistance, quality of life and functional autonomy of elderly individuals submitted to aquatic training R.1(1):6-9. J Aging Res Clin Practice. 2012;6-9.

2. Hirotomi T, Yoshihara A, Ogawa H, Miyazaki H. Association of dental status with vegetable intake in an elderly population. J Aging Res Clin Practice.
2012;84-7.

3. Dent E, Visvanathan R, Piantadosi C, Adams R, Lange K, Chapman I. Inflammatory cytokines and appetite in healthy people. J Aging Res Clin Practice. 2012;40-3.

4. Hao Q, Dong B, Huang C, Yanling Z, Luo L, Yue J. Smoking, Alcohol consumption, tea consumption, exercise and risk of depression among chinese nonagenarians. J Aging Res Clin Practice. 2012;74-9.

5. Tissue T, Wells L. Antecedent lifestyles and old age. Psychol Rep. 1971 Dec;29(3):1100.

6. Shephard RJ. The influences of race and environment on ischemic heart disease. Can Med Assoc J. 1974 Dec 21;111(12):1336-40.

7. Ekelund U, Steene-Johannessen J, Brown WJ, Fagerland MW, Owen N, Powell KE, et al. Does physical activity attenuate, or even eliminate, the detrimental association of sitting time with mortality? A harmonised metaanalysis of data from more than 1 million men and women. Lancet Lond Engl. 2016 Sep 24;388(10051):1302-10.

8. GBD 2017 Risk Factor Collaborators. Global, regional, and national comparative risk assessment of 84 behavioural, environmental and occupational, and metabolic risks or clusters of risks for 195 countries and territories, 1990-2017: a systematic analysis for the Global Burden of Disease Study 2017. Lancet Lond Engl. 2018 10;392(10159):1923-94.

9. Pahor M, Guralnik JM, Ambrosius WT, Blair S, Bonds DE, Church TS, et al. Effect of structured physical activity on prevention of major mobility disability in older adults: the LIFE study randomized clinical trial. JAMA. 2014 Jun 18;311(23):2387-96.

10. Dehghan M, Mente A, Zhang X, Swaminathan S, Li W, Mohan V, et al. Associations of fats and carbohydrate intake with cardiovascular disease and mortality in 18 countries from five continents (PURE): a prospective cohort study. Lancet Lond Engl. 2017 Nov 4;390(10107):2050-62.

11. GBD 2015 Tobacco Collaborators. Smoking prevalence and attributable disease burden in 195 countries and territories, 1990-2015: a systematic analysis from the Global Burden of Disease Study 2015. Lancet Lond Engl. 2017 May 13;389(10082):1885-906.

12. Hu M, Wu X, Shu X, Hu H, Chen Q, Peng L, et al. Effects of computerised cognitive training on cognitive impairment: a meta-analysis. J Neurol. 2019 Oct 24;

13. Wood AM, Kaptoge S, Butterworth AS, Willeit P, Warnakula S, Bolton T, et al. Risk thresholds for alcohol consumption: combined analysis of individualparticipant data for 599912 current drinkers in 83 prospective studies. Lancet Lond Engl. 2018 14;391(10129):1513-23.

14. Tak E, Kuiper R, Chorus A, Hopman-Rock M. Prevention of onset and progression of basic ADL disability by physical activity in community dwelling older adults: a meta-analysis. Ageing Res Rev. 2013 Jan;12(1):329-38.

15. Cao L, Tan L, Wang H-F, Jiang T, Zhu X-C, Lu H, et al. Dietary Patterns and Risk of Dementia: a Systematic Review and Meta-Analysis of Cohort Studies. Mol Neurobiol. 2016;53(9):6144-54.

16. Psaltopoulou T, Sergentanis TN, Panagiotakos DB, Sergentanis IN, Kosti R, Scarmeas N. Mediterranean diet, stroke, cognitive impairment, and depression: A meta-analysis. Ann Neurol. 2013 Oct;74(4):580-91.

17. Khera AV, Emdin CA, Drake I, Natarajan P, Bick AG, Cook NR, et al. Genetic Risk, Adherence to a Healthy Lifestyle, and Coronary Disease. N Engl J Med. 2016 15;375(24):2349-58.

18. Sabia S, Singh-Manoux A, Hagger-Johnson G, Cambois E, Brunner EJ, Kivimaki M. Influence of individual and combined healthy behaviours on successful aging. CMAJ Can Med Assoc J J Assoc Medicale Can. 2012 Dec 11;184(18):1985-92.

19. Ngandu T, Lehtisalo J, Solomon A, Levälahti E, Ahtiluoto S, Antikainen R, et al. A 2 year multidomain intervention of diet, exercise, cognitive training, and vascular risk monitoring versus control to prevent cognitive decline in at-risk elderly people (FINGER): a randomised controlled trial. Lancet Lond Engl. 2015 Jun 6;385(9984):2255-63.

20. Andrieu S, Guyonnet S, Coley N, Cantet C, Bonnefoy M, Bordes S, et al. Effect of long-term omega 3 polyunsaturated fatty acid supplementation with or without multidomain intervention on cognitive function in elderly adults with memory complaints (MAPT): a randomised, placebo-controlled trial. Lancet Neurol. 2017 May;16(5):377-89. 